\title{
Design and Implementation of Construction Material Management Scheme Based on RFID Technology
}

\author{
Henan four construction co., Ltd. Kaifeng 475000, Henan
}

\section{Introduction}

For the traditional construction materials, most of the semi-automatic management model, but this approach prone to human operation errors and other issues, the overall management efficiency is low, especially in the face of Blizzard, Tornado and other bad weather, the basic management model is not possible. Thus, to take RFID technology based on the material management program is to strengthen the important measures of material management. In fact, RFID technology has been widely used, its characteristics are: (1) penetrating, can penetrate building materials, mud and other building materials; (2) storage capacity, RFID tags can store large amounts of data information; (3) efficient identification, fast read recognition A variety of labels; (4) flexible operation, can increase the information, delete, modify and other operations; (5) high security, tag storage information coding protection, not easy to tamper with.

\section{Design Principles of Construc- tion Material Management}

The efficient construction materials management system can ensure that the material transport, enhance management efficiency, reduce material loss, deterioration and other issues generated frequency, but also reduce the cost of material storage monitoring labor costs, improve the utilization of building materials. RFID technology-based building construction materials management can adapt to a variety of harsh construction envi- ronments, such as snowstorms, tornadoes and other bad weather, or terrain bumps and other complex geographical location. It can be seen, the construction material management program design in accordance with the following principles:

(1) To ensure that the construction process, that is, due to lack of material lead to the construction process delay. Construction materials management to ensure that any construction process can continue to avoid delays in the construction process, which should effectively monitor the construction of the procurement of materials and the actual number of planned use.

(2) Reduce the construction costs due to excess material costs. In terms of a building project, the cost of materials and facilities is about $50 \%$ of the entire project, and the design cost is only about $10 \%$ of the cost. Therefore, the construction materials management program is designed to ensure the full use of materials.

(3) Reduce costs. Generally speaking, the so-called construction materials management is the material procurement, storage, inventory, requisition and other aspects of effective, intelligent management. Because the facilities or tags based on RFID technology can be used repeatedly, the cost of manpower is reduced to some extent, thereby reducing the overall construction cost.

(4) To enhance the efficiency of construction projects. In the

\begin{abstract}
With the improvement of construction demand and the reduction of land price, the construction of all kinds of buildings has become the current development trend in addition to the need for housing. Whether it is a large commercial center, office or landmark building, its construction materials in addition to enhancing the performance, but also to build an automated and effective material management system. This paper studies the design and implementation of the construction material management scheme based on RFID technology, hoping to improve the management system and improve the management efficiency through the application of RFID technology.
\end{abstract}

Key words: RFID technology; construction material management; design; implementation

Published online: 15th July, 2017

specific construction, often in the search, the use of materials or equipment to consume a lot of time, resulting in reduced construction efficiency. Construction materials management is based on this reduction of the time required to enhance the efficiency of the project.

(5) To ensure the safety and stability of the construction site. In this regard, the construction 
of materials management program designed to improve the scene of waste dumping of the problem, to ensure that the material to follow the design of the stack, so as to enhance the safety and stability of the construction site.

\section{Overall design of construction materials management program}

\subsection{Functional requirements design}

Material storage section: (1) to confirm the actual purchase of materials and the planned purchase amount is the same; (2) material transport in the information verification, to confirm whether and procurement the same; (3) material storage location confirmation; (4) material storage and data transmission to the material management System.

Material storage: (1) for the remaining amount of material below the minimum limit, it is necessary to promptly give a warning; (2) to the material management security monitoring, to avoid the emergence of material loss problems; (3) real-time update the remaining number of uploaded materials.
(2) To improve the accuracy of materials used to avoid the phenomenon of material misleading; (3) to update the uploading of materials in real time; (4) monitoring the delivery of the goods to send the goods; to improve the overall efficiency of materials; To the construction of the whole process.

\subsection{Information flow model}

In the design of construction materials management program, to its information flow analysis, sorting analysis of various aspects of construction materials, information

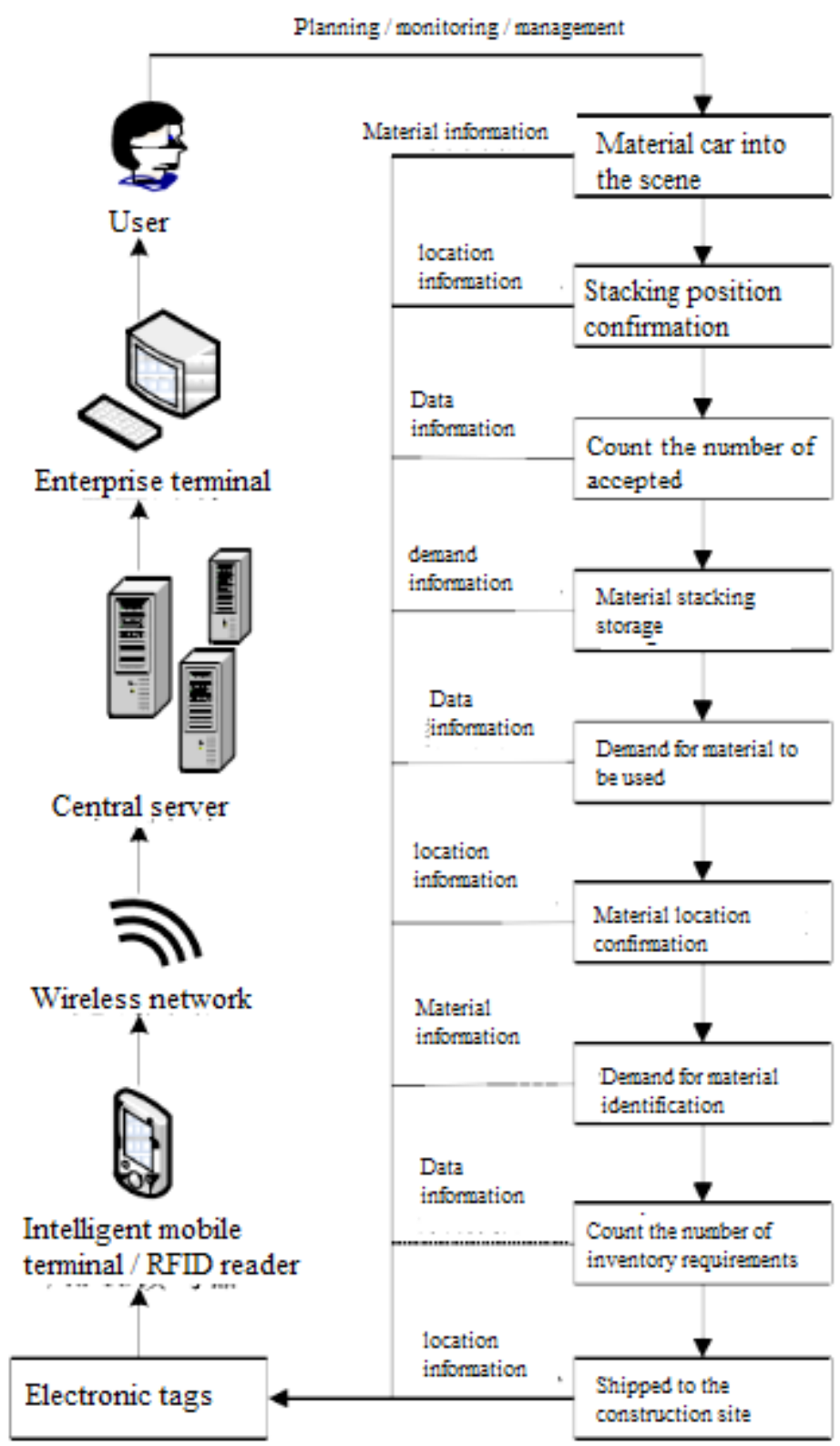

Figure 1 Building material management information flow model 
flow, the traditional open-loop information flow optimization for the closed-loop information flow, thereby enhancing the intensity of information monitoring, while building materials Management information flow model (see Figure 1 below).

\subsection{Overall structure}

According to the functional requirements analysis and information flow model of construction material management, the whole structure of material management is constructed, which includes five parts: user layer, application layer, service layer, data layer and hardware layer. The overall structure is shown in Figure 2 below.
3 Concrete construction materials management program specific design and implementation

3.1 Concrete design of construction materials management program

\subsubsection{Material storage link}

\subsubsection{Management plan}

In general, there are two sources of construction materials, one is the supplier procurement, in addition to standard material procurement, there are special materials procurement; the other is the construction company other completed works of the remaining materials. In the material supply mode to confirm and demand orders, will be served within the specified time. The original building construction materials are usually broken down into seven steps, as shown in Figure 3 below the dotted line left.

However, based on RFID technology, building materials management to improve the original process, will attach the RFID tag material through the construction site reader to scan, the whole link is simplified to four steps, the specific optimization is shown in Figure 3, dotted line right.

\subsubsection{Equipment arrangement}

In fact, the key to inventory the material when unloading is the RFID

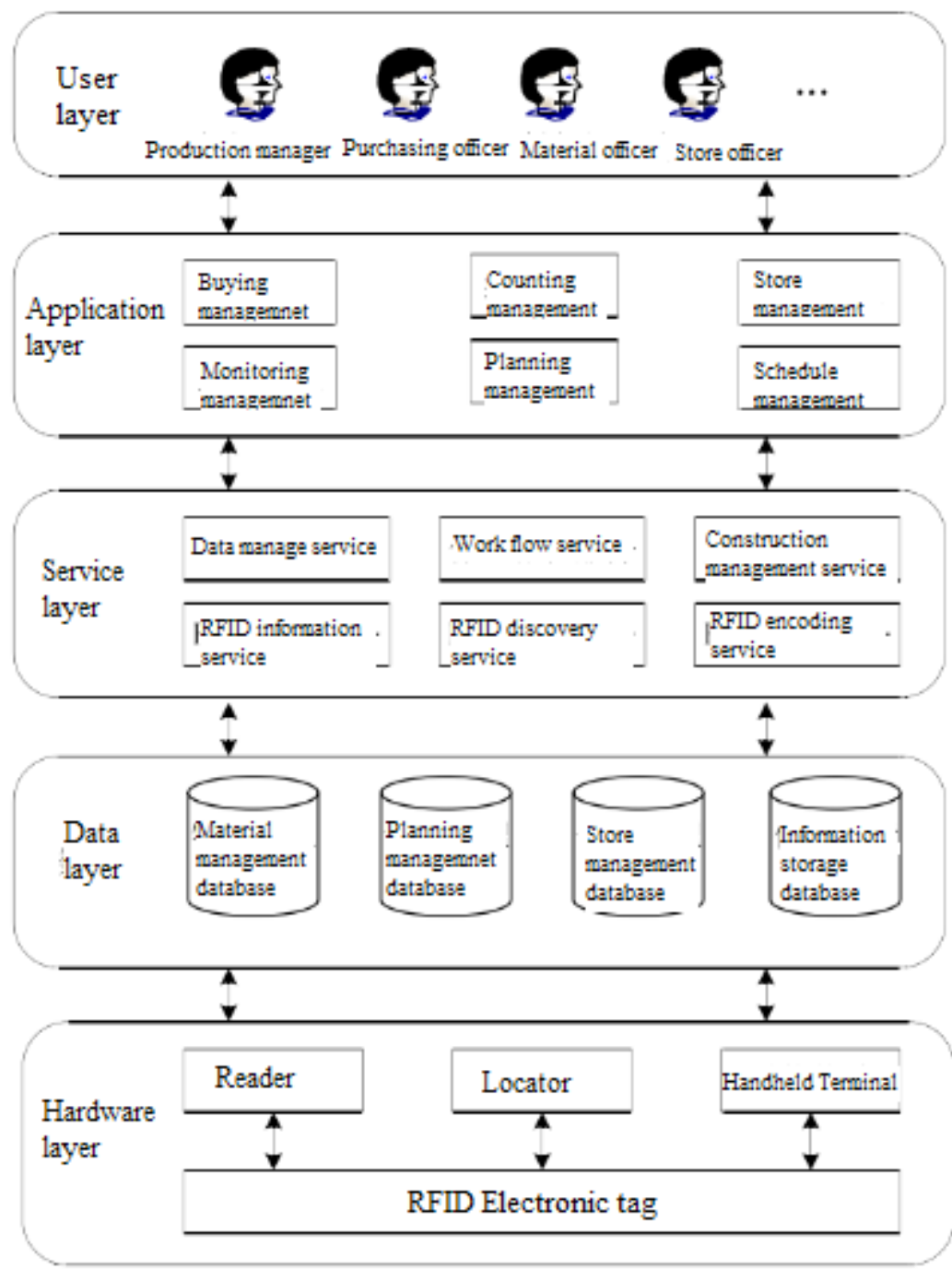

Figure 2 Building construction materials management of the overall structure 
reader installed around the material pile. In the material from the transport vehicle unloaded to the material rack or material pile at the same time, the reader scanned the label on the material, the system information update. So the material unloading at the same time, the number of inventory is also completed. After the management system will calculate the increase in the label, and plan to purchase the number of comparisons, if the two are the same, the system will automatically carry out material storage operations, and feedback information to the terminal equipment; if the two are different, will issue a warning reminder. The construction equipment storage program management program equipment arrangement shown in Figure 4.

\subsubsection{Material storage links}

\subsubsection{Management plan}

For the storage of construction materials, to ensure the safety of materials to avoid the loss of materials, theft, etc., at the same time to update the remaining amount of material upload, to facilitate the procurement of procurement arrangements to ensure that the construction process. For real-time updates of the remaining quantity of material, the purpose is to alert the remnants of the remaining quantity near the minimum limit, thereby facilitating

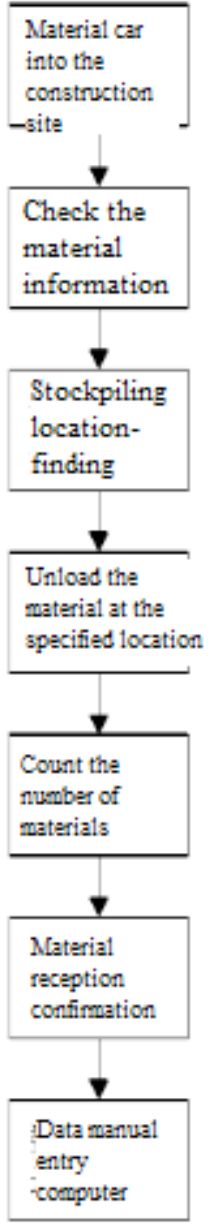

Original work flow

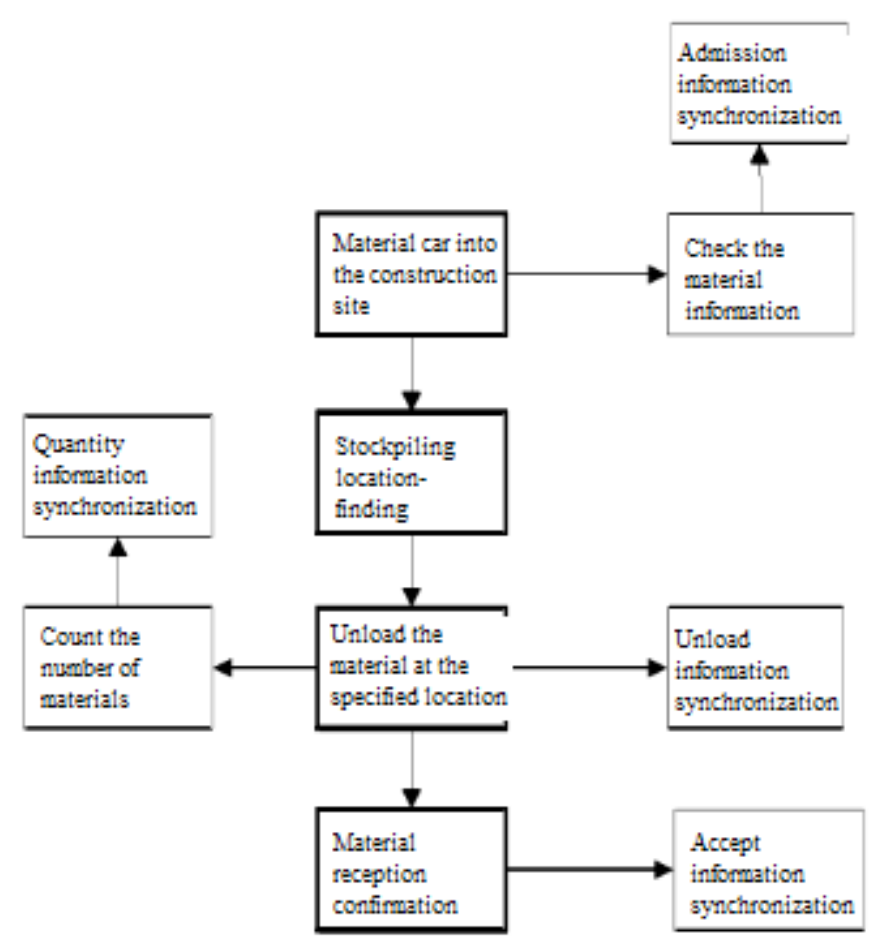

Optimized work flow

Figure 3 Material storage process flow comparison 
the manager's understanding of the construction process and the material situation. It can be seen that the warning of the remaining amount of material is the key to the design of the material storage.

\subsubsection{Equipment arrangement}

There are two cases for the storage of materials in the material storage area. The first is the material stored in the material rack. Generally, the receiver and the reader are installed on the material rack. If the material attached to the label leaves the receiver range, Upload to the management system, real-time update system class material information; the second is no material racks directly stacked materials, such materials are often stored in the fence, etc., can be in the material pool, fence and the like around the device to install the receiver And the reader, the specific location of the construction site with the confirmation of the scene.

\subsubsection{Materials to take links}

\subsubsection{Management plan}

In the construction of materials, the emergence of the so-called materials used in the link. In the construction materials needs to be approved by the manager, you can go to the warehouse staff to receive demand materials. The whole process can be subdivided into multiple steps, as shown in Figure 5 below.

RFID-based material management can improve the original process, the installation of the RFID reader onsite material transport equipment to simplify the original process, the specific flow chart is shown in Figure 5 dotted line right.

\subsubsection{Equipment arrangement}

RFID tags are set up in various plac- es in the field. Since the RFID reader is installed in the equipment such as tower crane, trolley and so on, the label is automatically scanned every time the material is transported, and then transmitted to the system through the signal receiver, which is convenient for managers' use. However, the location of the label requirements, the installation of complex, ordinary construction projects should not be used. The design and arrangement of the construction materials are shown in Figure 6 below.

3.2 Implementation of construction materials management program

In general, the implementation of the construction material management program can be divided into three steps:

Design planning: clear engineering materials needs $\rightarrow$ to develop the

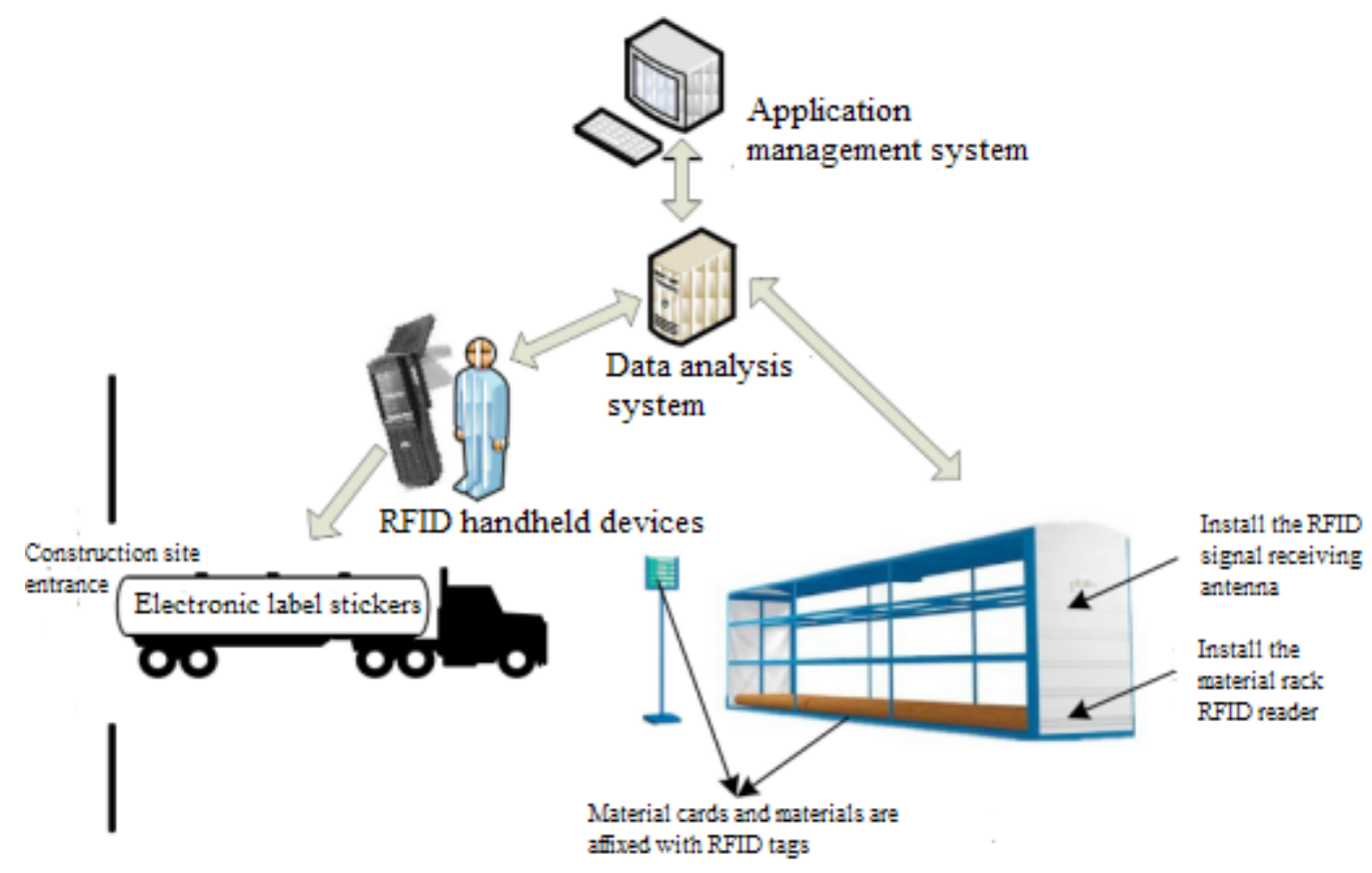

Figure 4 Construction materials storage link to achieve and facilities arrangements 
construction process $\rightarrow$ clearly monitor the type of material $\rightarrow$ clear corresponding to the RFID device $\rightarrow$ clear equipment installation location;

Environmental construction: RFID equipment installation $\rightarrow$ build a wireless network environment $\rightarrow$ build management system;

Preparations: Equipment Trial $\rightarrow$ Personnel Technical Training.
The first step design planning links, managers should be combined with the scale of construction projects to confirm the material needs, planning materials management steps to confirm the construction materials category, equipment type and the corresponding installation location, where RFID equipment, including readers, Signal receiver and so on. The second step environment construction links, the use of a wireless router to achieve the construction site net- work coverage, but also for RFID equipment and the installation of hardware equipment. The third step is to prepare the link, the installation of equipment and construction links to test the operation to ensure the normal operation of equipment and environmental stability, in addition, but also the relevant personnel for theoretical and technical training. After the above three steps are completed, the construction materials management program really into the

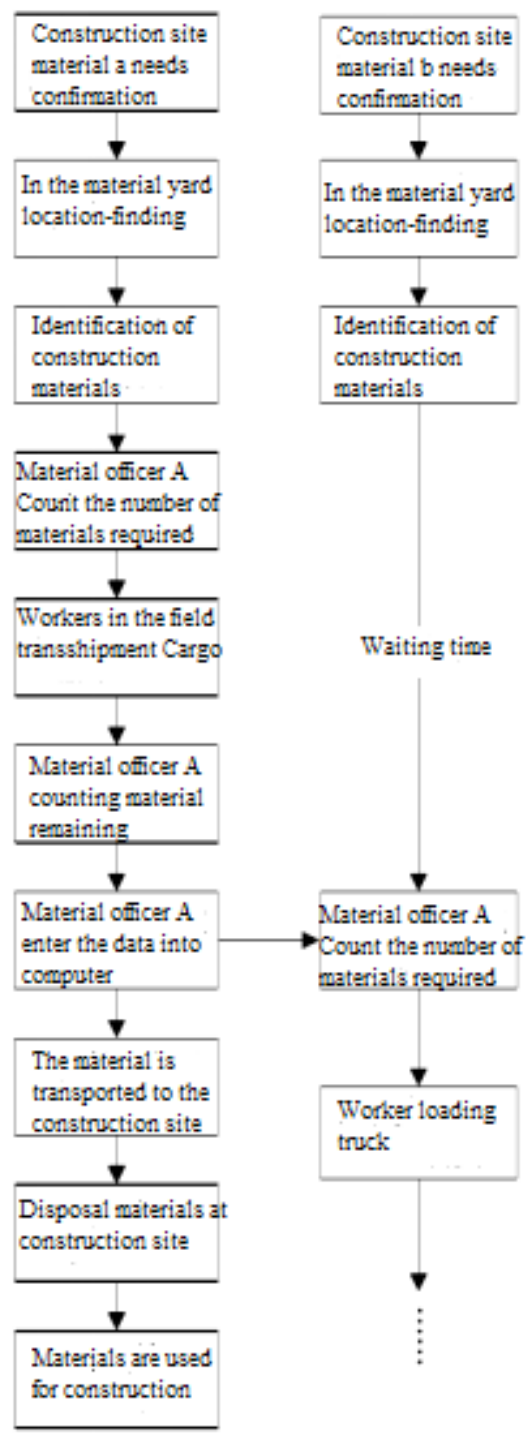

The original process

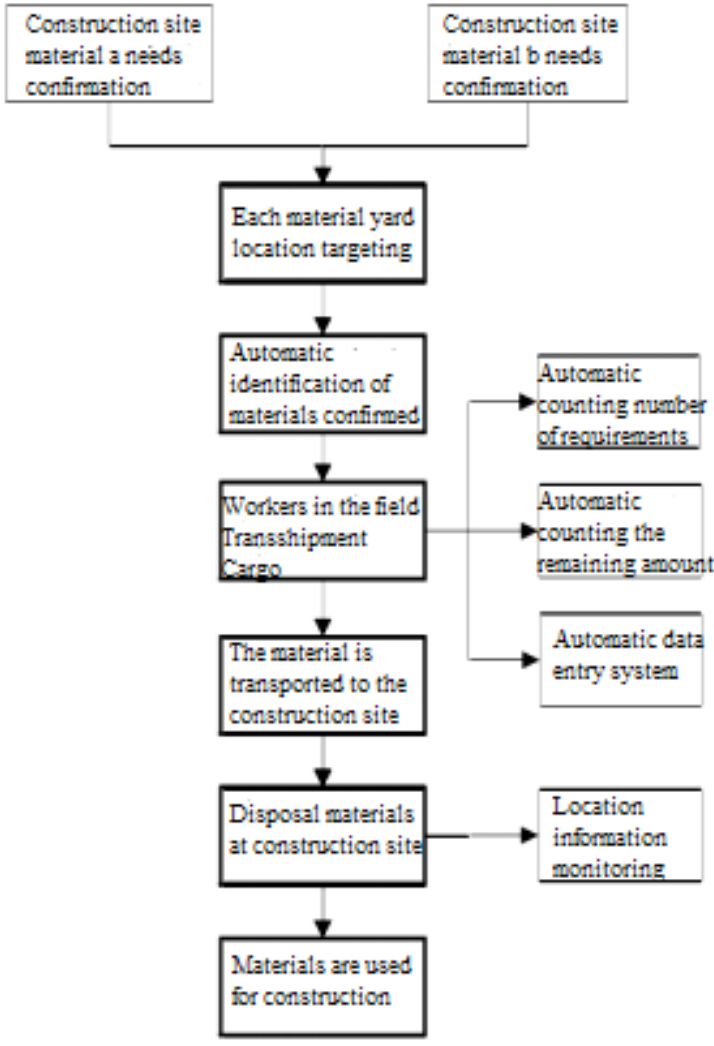

The optimized process

Figure 5 Comparison of materials used in the link process 
implementation phase.

\section{Conclusion}

In general, the design and implementation of building materials management scheme based on RFID technology have an important influence on the construction site material monitoring and management. Such as optimizing the construction process, the use of automatic data collection technology makes the construction process simplistic; open the work process, material management system records the scene of the various links, and open and transparent; reduce costs, RFID tags can be used repeatedly, Can reduce costs and so on. It can be seen that the use of RFID technology in the construction of materials management has practical value and long-term significance.

\section{References}

[1] Liao Yan, Lu Yaobin. RFID technology in the supply chain management application research [J]. Logistics Science and Technology .2008 (03)

[2] Xu Yin. Design of industrial production logistics based on RFID [J]. Industrial Design .2015 (05)

[3] Hu Rongsong, Liu Lilan, Yu Tao. Study on wireless data acquisition technology using radio frequency identification [J]. Modern Manufac- turing Engineering .2012 (07)

[4] Yang Jin, Wang Zheng .J2EE platform based on RFID single production monitoring [J]. Computer Engineering and Design .2011 (05)

[5] Qiu Shaofeng, Huang Chaoming. Design and Implementation of Active RFID Tag Test Platform [J]. Automation \& Instrumentation 2010 (04)

[6] Hu Xiangdong, An Dongyang. Analysis and Design of Automobile Production Logistics Tracking Management System Based on RFID [J]. Application Research of Computers .2008 (12)

[7] Liu Jun, Xue Ming, Li Guili. RFID

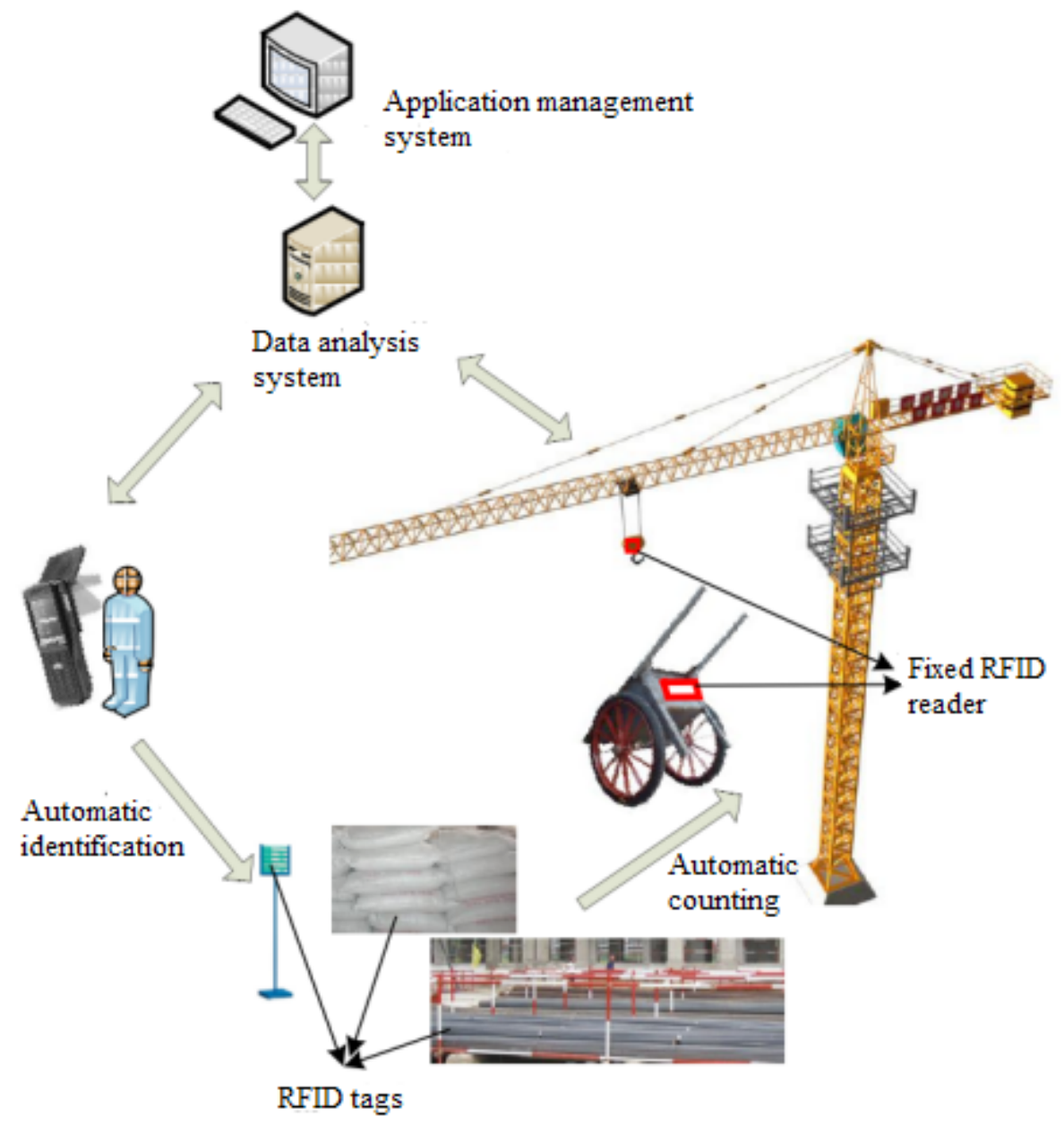

Figure 6 construction materials used in the design and arrangements 
Vehicle Identification and Information Processing in Automobile Production [J]. Manufacturing Automation .2006 (12)

[8] PAN Lei, CHEN Gui-hui, LI Ke. Improvement of Binary Anti-Collision Algorithm in RFID System [J]. Automation and Instrumentation 2015 (07)

[9] Geng Xuefei. RFID Technology in the Supply Chain Management Application [J]. Logistics Science and Technology .2005 (07)

[10] MENG Xiang-zhong, ZHANG Zhi-gang, LI Zong-ming. Study On
Tracking and Monitoring System of Mine Transportation Vehicle Based on RFID Technology [J]. China Coal $.2012(04)$

[11] WANG Ting-kui, ZHAO Yi-jie, ZHANG Rui-yi, LI Yang. Study on Construction Maintenance Management System of Construction Equipment Based on BIM and RFID [J]. Construction Economy .2013 (11)

[12] Esin Ergen, Burcu Akinci, Rafael Sacks. Tracking and Locating Components In A Precast Storage Yard Utilizing Radio Frequency Identification Technology And GPS[J]. Automation in Construction.2006 (3)
[13] R. Navon, O.Berkovich. An Automated Model For Materials Management And Control [J]. Construction Management and Economics.2006 (6)

[14] George Q.Huang, Y.F.Zhang, X.Chen, Stephen T. Newman. RFID-Enabled Real-Time Wireless Manufacturing for Adaptive Assembly Planning and Control [J]. Journal of Intelligent Manufacturing.2008 (6)

[15] KurtHozak, David A.Collier. RFID as an Enabler of Improved Manufacturing Performance[J].Decision Sciences.2008 (4) 